\title{
Interactions, structure and properties in poly(lactic acid)/thermoplastic polymer blends
}

\author{
B. Imre $e^{1,2^{*}}$, K. Renner ${ }^{1,2}$, B. Pukánszky $y^{1,2}$ \\ ${ }^{1}$ Laboratory of Plastics and Rubber Technology, Department of Physical Chemistry and Materials Science, Budapest \\ University of Technology and Economics, H-1521 Budapest, P.O. Box 91, Hungary \\ ${ }^{2}$ Institute of Materials and Environmental Chemistry, Research Centre for Natural Sciences, Hungarian Academy of \\ Sciences, H-1525 Budapest, P.O. Box 17, Hungary
}

Received 5 July 2013; accepted in revised form 26 August 2013

\begin{abstract}
Blends were prepared from poly(lactic acid) (PLA) and three thermoplastics, polystyrene (PS), polycarbonate (PC) and poly(methyl methacrylate) (PMMA). Rheological and mechanical properties, structure and component interactions were determined by various methods. The results showed that the structure and properties of the blends cover a relatively wide range. All three blends have heterogeneous structure, but the size of the dispersed particles differs by an order of magnitude indicating dissimilar interactions for the corresponding pairs. Properties change accordingly, the blend containing the smallest dispersed particles has the largest tensile strength, while PLA/PS blends with the coarsest structure have the smallest. The latter blends are also very brittle. Component interactions were estimated by four different methods, the determination of the size of the dispersed particles, the calculation of the Flory-Huggins interaction parameter from solvent absorption, from solubility parameters, and by the quantitative evaluation of the composition dependence of tensile strength. All approaches led to the same result indicating strong interaction for the PLA/PMMA pair and weak for PLA and PS. A general correlation was established between interactions and the mechanical properties of the blends.
\end{abstract}

Keywords: polymer blends and alloys, poly(lactic acid), dispersed structure, miscibility, structure-property correlations

\section{Introduction}

The interest in using polymeric materials derived from renewable resources increases continuously because of the considerably improved environmental awareness of society and the fear from the depletion of petrochemical based plastics [1]. Poly(lactic acid), PLA, seems to be the polymer which exploits the most successfully this surge of demand for such materials and satisfies the requirements of large scale processing and application at the same time. PLA has several advantages, among others it can be produced from renewable resources [2] thus its application does not generate supplementary $\mathrm{CO}_{2}$ emission [3], it is recyclable and compostable, and it has good stiffness and strength. On the other hand, this polymer has some drawbacks as well, including moisture sensitivity, fast physical ageing, poor impact resistance and relatively high price [46]. As a consequence, many attempts are made to modify it by plasticization [7-13], copolymerization [14-19], blending [20,21] or by the production of composites [11-13, 22-30].

The modification of polymers by blending is a mature technology developed in the $70^{\text {ies }}$ or even earlier. A large number of papers and books were published on the topic [31-43], and the theoretical studies carried out mostly on commodity and engineering thermoplastics paved the way for industrial applications. The advent of biopolymers resulted in a revival of blending technology, as their several

\footnotetext{
${ }^{*}$ Corresponding author, e-mail: bimre@mail.bme.hu (C) BME-PT
} 
disadvantages can be overcome by blending. The number of papers on the blending of biopolymers is vast, partly because of the huge number and wide diversity of these polymers and partly because of the increased interest in them. PLA and starch are the most often studied materials [36-45], but one could mention poly(3-hydroxybutyrate-co-3-hydroxyhexanoate)/poly(vinyl phenol) [46], thermoplastic phenol formaldehyde resin/poly(E-caprolactone) (PCL) [47], poly(3-hydroxybutyrate) (PHB)/PCL [48], PLA/poly(butylene succinate) (PBS) [49, 50], poly(3-hydroxybutyrate-co-3-hydroxihexanoate)/poly (lactic acid) (PLA) [51], PHB/PLA [52], etc. without even attempting to be comprehensive. The goals of blending can range from the modification of $T_{\mathrm{g}}$, increase of fracture resistance, flexibility or processability to the improvement of some other properties like optical characteristics or flammability.

Miscibility is often mentioned in papers dealing with the blends of bio-based and biologically degradable polymers, but rarely investigated in detail in all its various aspects. Phase diagrams and the mutual solubility of the components in each other are not determined, only the fact is established that a homogeneous or heterogeneous blend forms. The conclusion is usually based on the number of glass transition temperatures detected or on the number of phases observed on SEM micrographs. However, all polymers are partially miscible and dissolve in each other in some extent, and mutual solubility depends on interaction, which can be characterized by the Flory-Huggins interaction parameter $(\chi)$, for example. Although interactions are complicated and the parameter is rather complex consisting of various components [53], the approach is the simplest from the practical point of view and it is widely used for the estimation of miscibility [19, 54-56].

Fully degradable PLA blends may be used in agriculture and packaging, but engineering applications require more durability and longer lifetime. As a consequence, PLA is blended not only with other bio-based or biodegradable polymers, but also with commodity and/or engineering plastics [57] usually for the automotive or the electronic industry. Several commercial applications exist already for such blends [57]. The application of such materials also has environmental benefits since they improve carbon footprint considerably. However, the production of such blends with properties satisfying the intended application is possible only if the interac- tion of the components is controlled and miscibilitystructure-property correlations are known. Accordingly, the goal of this work was to study interactions, structure and properties in the blends of PLA with three commercial thermoplastics with differing chemical structures. Polystyrene (PS), polycarbonate (PC) and poly(methyl methacrylate) (PMMA) were selected as blend components, because these thermoplastics are available in large quantities, possess excellent properties and are rated among the most common polymers applied for the production of commercially available PLA based blends [57]. Interactions were estimated quantitatively and an attempt was made to relate miscibility, structure and properties in the studied blends.

\section{Experimental}

The poly(lactic acid) (PLA) used in the experiments was obtained from NatureWorks LLC (Minnetonka, $\mathrm{MN}, \mathrm{USA}$ ). The selected grade (Ingeo 4032D, $M_{\mathrm{n}}=$ $88500 \mathrm{~g} / \mathrm{mol}$ and $\left.M_{\mathrm{w}} / M_{\mathrm{n}}=1.8\right)$ is recommended for extrusion. The polymer $(<2 \% \mathrm{D}$ isomer) has a density of $1.24 \mathrm{~g} / \mathrm{cm}^{3}$, while its MFI is $3.9 \mathrm{~g} / 10 \mathrm{~min}$ at $190^{\circ} \mathrm{C}$ and $2.16 \mathrm{~kg}$ load. The thermoplastics used to prepare the blends were PS (Styron 686E, Styron LLC, Berwyn, PA, USA, density: $1.05 \mathrm{~g} / \mathrm{cm}^{3}$, MFI: $2.5 \mathrm{~g} / 10 \mathrm{~min}$ at $200^{\circ} \mathrm{C}, 5 \mathrm{~kg}$ ), PC (Makrolon 2658, Bayer Material Science AG, Leverkusen, Germany, density: $1.2 \mathrm{~g} / \mathrm{cm}^{3}$, MFI: $13 \mathrm{~g} / 10 \mathrm{~min}$ at $300^{\circ} \mathrm{C}$, $1.2 \mathrm{~kg}$ ) and PMMA (Oroglas HFI 7-101, Arkema Inc., King of Prussia, PA, USA, density: $1.17 \mathrm{~g} / \mathrm{cm}^{3}$, MFI: $10 \mathrm{~g} / 10 \mathrm{~min}$ at $230^{\circ} \mathrm{C}, 3.8 \mathrm{~kg}$ ). Composition changed from 0 to $100 \mathrm{vol} \%$ of the second component in $10 \mathrm{vol} \%$ steps. Before processing PLA was dried in a vacuum oven $\left(110^{\circ} \mathrm{C}\right.$ for 4 hours $)$, while PS, PMMA and PC were dried in an air circulating oven for 2 hours at 80,90 and $120^{\circ} \mathrm{C}$, respectively. PLA and the thermoplastics were homogenized in an internal mixer (Brabender W 50 EHT, Brabender GmbH \& Co. KG, Duisburg, Germany) for $12 \mathrm{~min}$ at $190^{\circ} \mathrm{C}$ and $50 \mathrm{rpm}$. Both temperature and torque were recorded during homogenization. The melt was transferred to a Fontijne SRA 100 (Fontijne Grotnes B.V., Vlaardingen, The Netherlands) compression molding machine $\left(190^{\circ} \mathrm{C}, 5 \mathrm{~min}\right)$ to produce $1 \mathrm{~mm}$ thick plates used for further testing.

One way to estimate interactions was to measure the solvent uptake of the polymers and the blends. The measurements were carried out in a desiccator by placing $20 \times 20 \times 1 \mathrm{~mm}$ compression molded spec- 
imens into the vapor of dimethyl sulfoxide (DMSO (Scharlab S.L., Barcelona, Spain) and decane (Alfa Aesar GmbH \& Co KG, Karlsruhe, Germany) at $25^{\circ} \mathrm{C}$ as a function of time until equilibrium was reached. Flory-Huggins interaction parameters were calculated from the equilibrium solvent uptake of the samples according to a method described earlier [58]. The glass transition temperature of the blends was determined by dynamic mechanical analysis (DMA) using a Perkin Elmer Diamond DMA (PerkinElmer Inc., Massachusetts, MA, USA) apparatus. Measurements were done in tensile mode with constant amplitude $(10 \mu \mathrm{m})$ and frequency $(1 \mathrm{~Hz})$ from 0 to $200^{\circ} \mathrm{C}$ with a heating rate of $2{ }^{\circ} \mathrm{C} / \mathrm{min}$. The glass transition temperature of the components and the blends was determined also by scanning calorimetry on $5 \mathrm{mg}$ samples at $10^{\circ} \mathrm{C} / \mathrm{min}$ heating rate in two runs. Rheological measurements were carried out using an Anton-Paar Physica MCR 301 (Anton Paar GmbH, Graz, Austria) apparatus at $210^{\circ} \mathrm{C}$ in oscillatory mode in the frequency range of $0.1-6001 / \mathrm{sec}$ on discs with $25 \mathrm{~mm}$ diameter and $1 \mathrm{~mm}$ thickness. The amplitude of the deformation was $2 \%$. The morphology of the blends was studied by scanning electron microscopy (JEOL JSM-6380 LA, JEOL Ltd., Tokyo, Japan). Micrographs were taken from cryo-fractured surfaces. Mechanical properties were characterized by tensile testing on standard $1 \mathrm{~mm}$ thick ISO 527 specimens using an Instron 5566 (Instron, Norwood, MA, USA) apparatus. Stiffness $(E)$ was determined at $0.5 \mathrm{~mm} / \mathrm{min}$ cross-head speed and $50 \mathrm{~mm}$ gauge length. Tensile strength $(\sigma)$, and elongation-at-break $(\varepsilon)$ were calculated from force vs. deformation traces measured on the same specimens at $5 \mathrm{~mm} / \mathrm{min}$ cross-head speed.

\section{Results and discussion}

The results are discussed in several sections. The composition dependence of properties is presented first than the structure developing during processing is discussed in the next section. A longer section is dedicated to the estimation of interactions by several methods and miscibility-structure-property interactions are discussed in the last section of the paper.

\subsection{Properties}

The composition dependence of blend properties is determined by the interaction of the components, structure, but also by the property itself. Modulus is less sensitive to changes in interaction and structure, while properties measured at larger deformations usually indicate quite well the interaction (compatibility) of the components. As a consequence, the study of the composition dependence of properties may offer information about the interaction of the components. Complex viscosity determined at $0.2 \mathrm{~s}^{-1}$ angular frequency is plotted against composition in Figure 1 for the three series of blends. The correlations offer rather dissimilar picture. The simplest is the composition dependence of PLA/ PMMA blends, since the viscosity of the blends changes practically linearly between those of the two polymers. Additivity indicates good homogeneity and not too strong specific interactions between the components. Extremes in the composition dependence of viscosity are frequently claimed to indicate the strength of interaction; maxima are related to strong, while minima to poor interactions. Accordingly, the interaction of PC to PLA is expected to be stronger than that of PS. However, we must consider here other factors like the size of the dispersed droplets, their elasticity and interfacial tension, which also influence the actual value of viscosity, thus far reaching conclusions cannot be drawn about interactions from Figure 1.

The composition dependence of modulus (not shown) offers even less information, it changes almost linearly with composition for all three polymer pairs. The inherent stiffness of the three thermoplastics used in the study is close to that of PLA, it changes

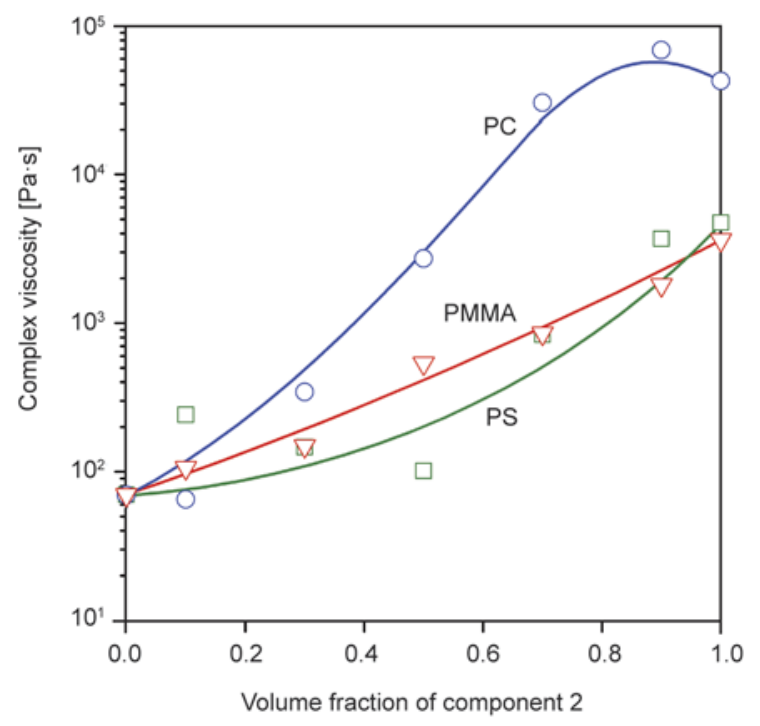

Figure 1. Composition dependence of the complex viscosity of PLA/thermoplastic polymer blends determined at $0.2 \mathrm{~s}^{-1}$ angular frequency; ( $\square$ ) PS, ( ०) PC, ( $\nabla)$ PMMA 


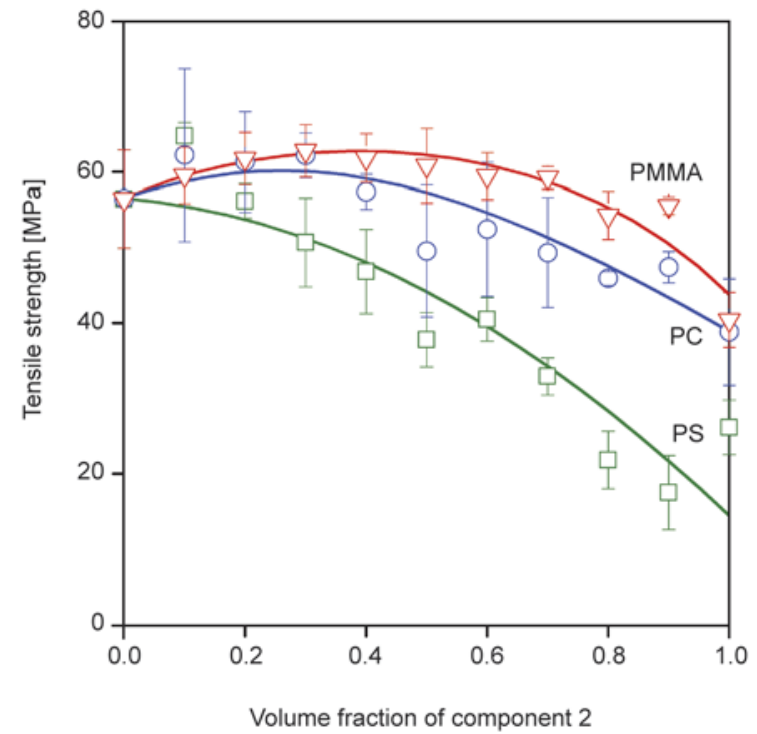

Figure 2. Tensile strength of PLA/thermoplastic polymer blends plotted against the amount of the second component; ( $\square)$ PS, (O) PC, ( $\nabla)$ PMMA

between 2.0 and $3.1 \mathrm{GPa}$, while that of PLA is 3.2 GPa. We mentioned already, that modulus is not very sensitive to structure and interactions. The composition dependence of tensile strength shows more variation (Figure 2). The three sets of blends can be distinguished clearly, PMMA blends are the strongest, while PS blends have the smallest tensile strength; the strength of the PC blends runs in between. Such differences in the composition dependence of strength were shown to be related to interactions earlier $[59,60]$, thus we expect the

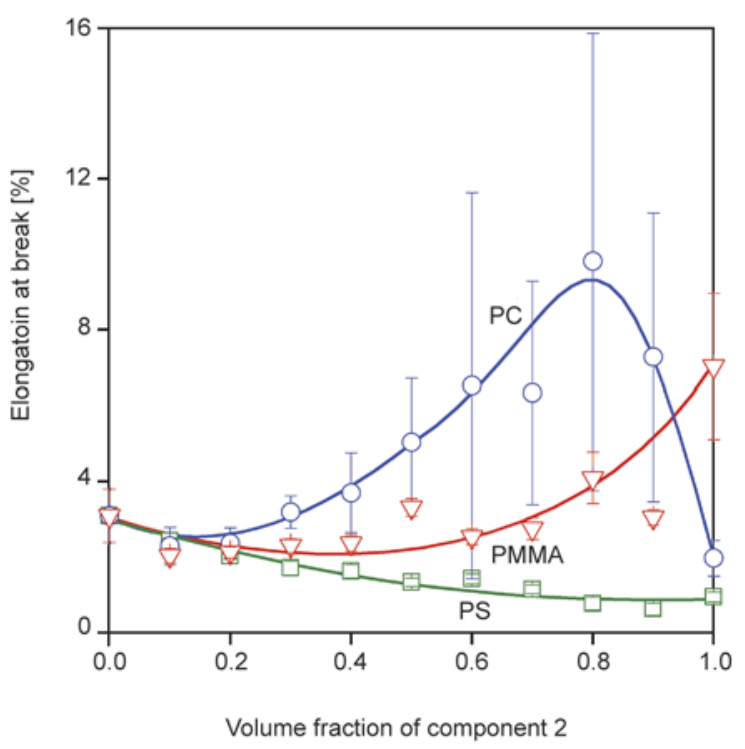

Figure 3. Effect of composition and the type of the second component on the deformability of PLA/thermoplastic polymer blends; ( $\square)$ PS, (०) PC, $(\nabla)$ PMMA strongest interactions to develop in PMMA while the weakest in PS blends. The deformability of the blends offers a more complex picture again. PLA/ PS blends are very brittle; they fail at very small elongations (Figure 3). The elongation-at break of the PMMA blends changes continuously with composition, it is not very large, but larger than that of the PS blends. The deformability of the PC blends is interesting; it exhibits a maximum in the range of 70 and 90 vol\% PC, although we have to emphasize that the standard deviation of the elongation-atbreak values for PLA/PC blends is considerable in this composition range. The maximum might indicate changes in interactions, structure or deformation mechanism as a result of the presence of the PLA dispersed phase, but without the thorough analysis of micromechanical deformation processes we have to refrain from drawing further conclusions. Nevertheless, the phenomenon is definitely beneficial from the practical point of view.

\subsection{Structure}

The structure of the blends was studied by SEM. Miscible blends are usually homogeneous and transparent [e.g. PS/poly(phenylene oxide) (PPO)]. On the other hand, immiscible blends have heterogeneous structure, very often the particles of one component are dispersed in the matrix formed by the other. However, depending on interactions particle size may change in a wide range. Weak interactions result in large particles, often in the range of $10 \mu \mathrm{m}$ like in the blends of PP and PVC, while good interactions lead to small dispersed particles of several tenth of a micron (e.g. PVC/PMMA). Blend structure is shown as a function of composition in Figure 4 for the three series of blends. Large particles form in the PLA/PS blends and particle size shows a maximum at around $50 \mathrm{vol} \%$ PS content. Such large particles indicate poor interactions as indicated above. The opposite is valid for the PMMA blends. Both phases are dispersed as very small particles in the other component at the two ends of the composition range. The particles are hardly visible at the magnification used, but they are there as shown by Figure 5, in which blend structure is presented at larger magnification. At 30 vol\% PMMA content small PMMA particles are dispersed in the PLA matrix. It is a little strange that a co-continuous structure cannot be distinguished even at 0.5 volume fraction of PMMA, although the 
small size of the particles indicate good interactions, and phase transition usually occurs in a wide
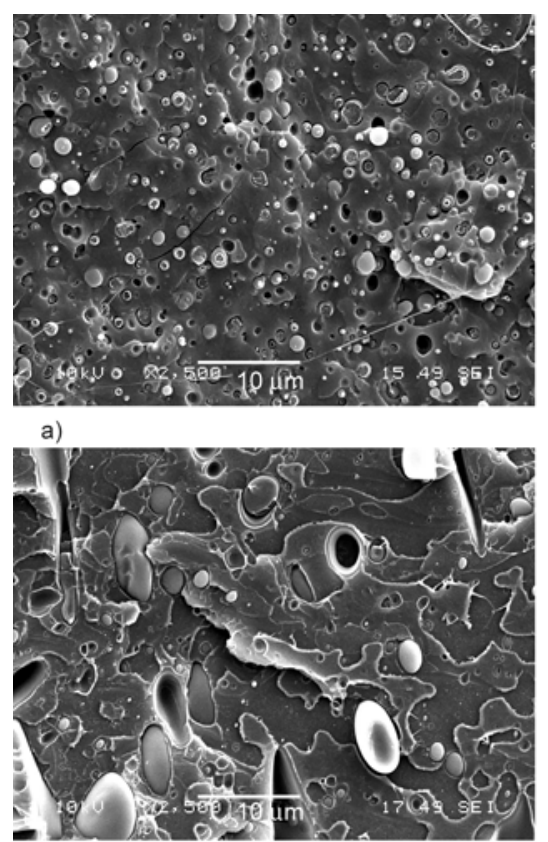

d)

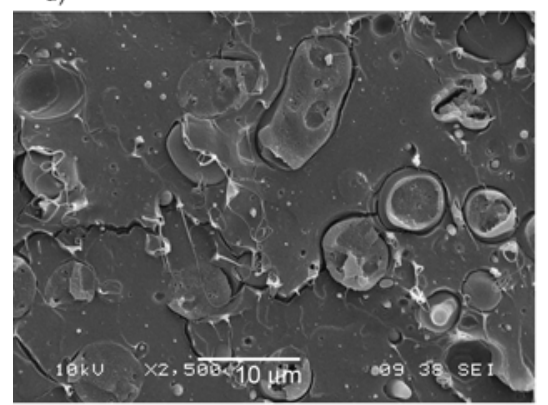

g)

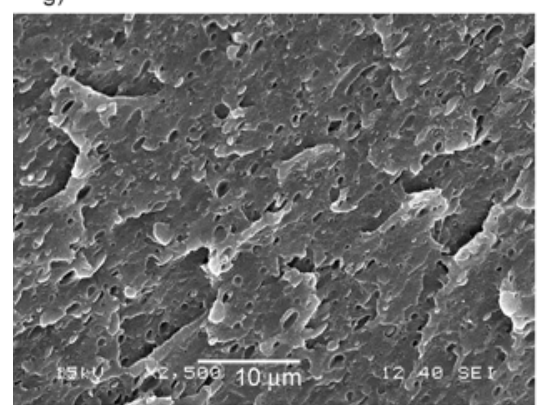

j)

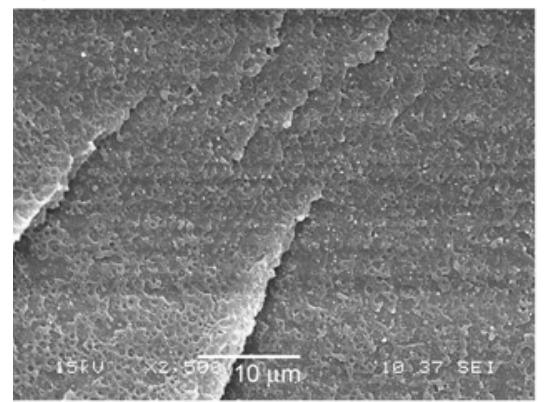

m)

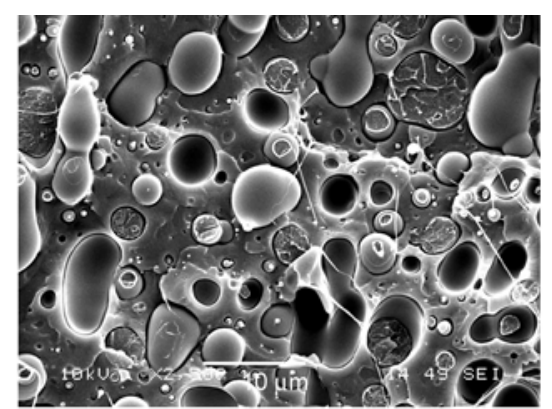

b)

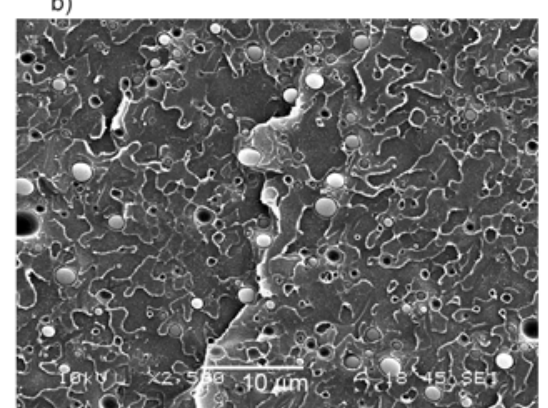

e)

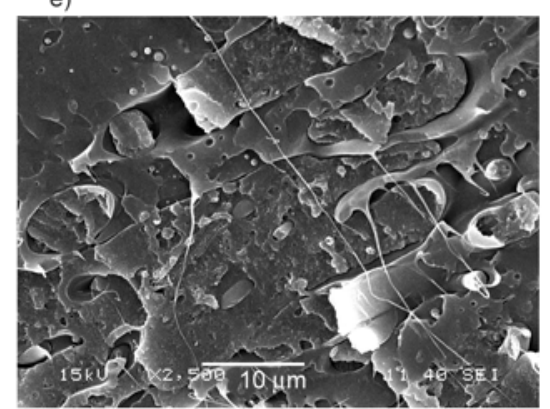

h)

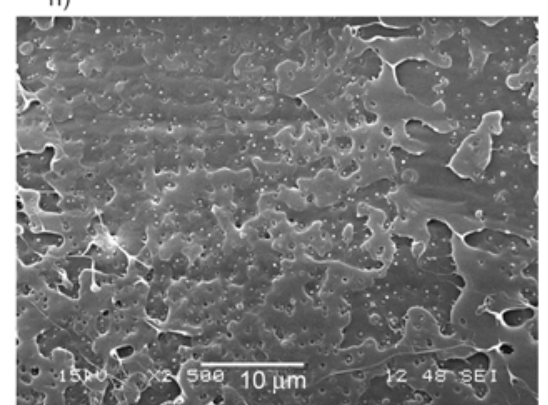

k)

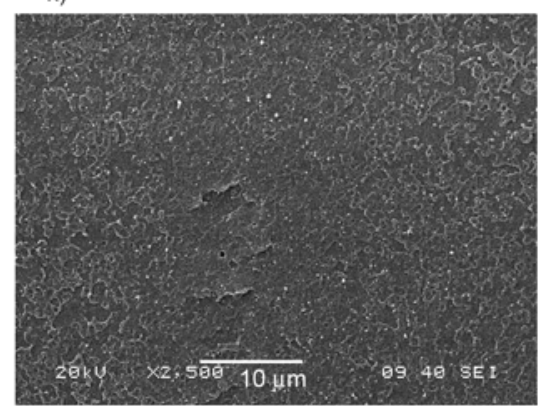

n)
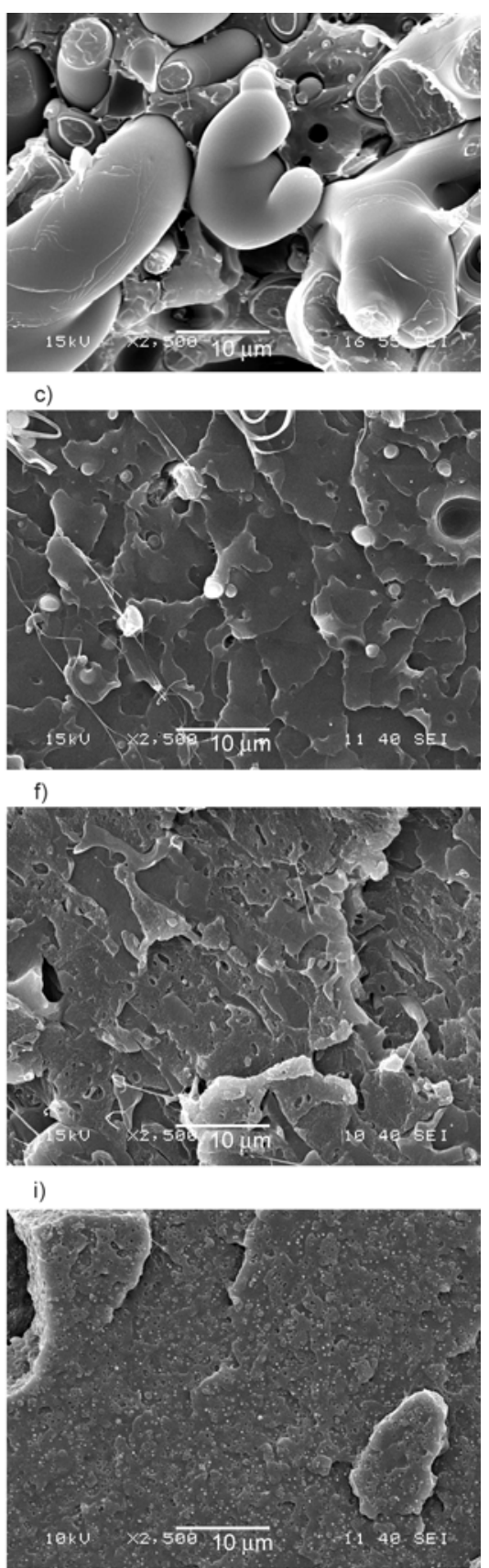

I)

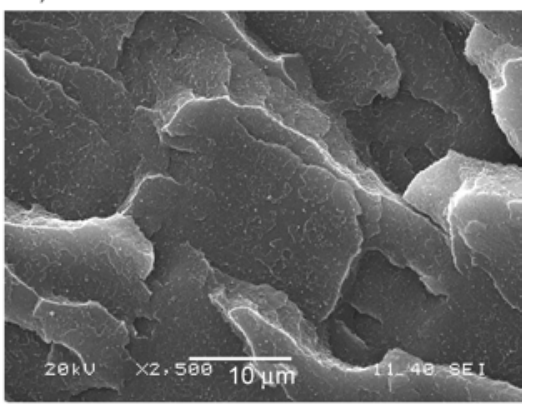

o)

Figure 4. Changes in the morphology of PLA/thermoplastic polymer blends (a-e PLA/PS, f-j PLA/PC, k-o PLA/PMMA) with composition $(0.1,0.3,0.5,0.7$ and 0.9 volume fraction) and component interactions 


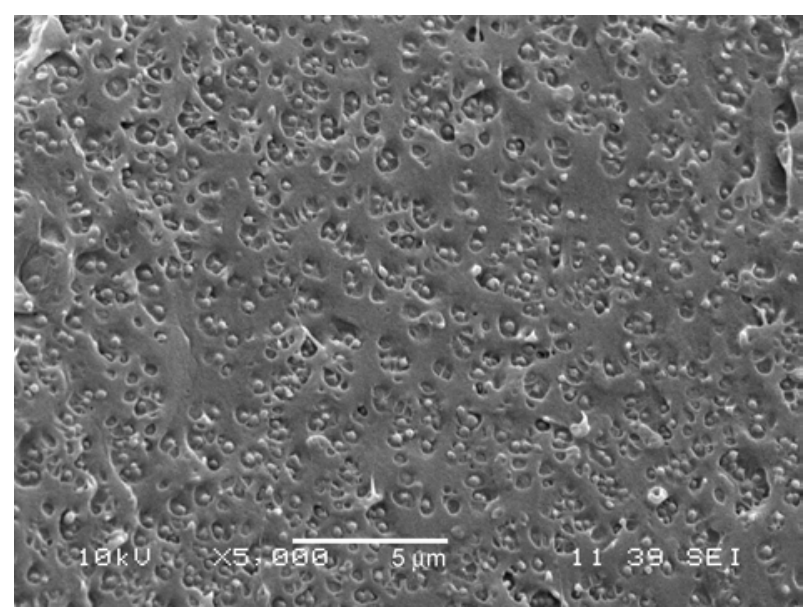

Figure 5. Dispersed structure of the PLA/PMMA blend containing $30 \mathrm{vol} \%$ PMMA shown in larger magnification than in Figure 4

develop at the PLA side of the composition range, while rather small ones when $\mathrm{PC}$ is the matrix. This might indicate different solubility of the components in each other, although we have to draw the attention here to the fact that several other factors determine particle size in polymer blends besides interfacial interactions. Component viscosity, as well as processing conditions affect morphology to a great extent. During processing, large pieces of one component are dispersed in the matrix at short mixing times, and the dominating process is particle break-up. The size of dispersed particles decreases as a function of mixing time until an equilibrium is reached between break-up and coalescence [61]. Several different models aim to describe the factors affecting this process and the final morphology [61-67]. According to them, equilibrium particle size is assumed to depend on numerous factors including composition, shear rate, the relative viscosity and interfacial tension of the components, degradation, energy required for particle break-up, coalescence probability, etc. The viscosity of PC is of several magnitudes larger than that of PLA, which might result in the formation of considerably different blend structures at the two sides of the composition range, i.e. in PLA and PC matrices, respectively, as observed in PLA/PC blends.

The particle size of the dispersed phase was determined quantitatively in the blends. The results are presented in Figure 6. The correlations reflect the qualitative analysis discussed above; relatively large particles and a maximum in the PS, very small ones in the PMMA blend and asymmetric composition dependence for the PC blends. According to these

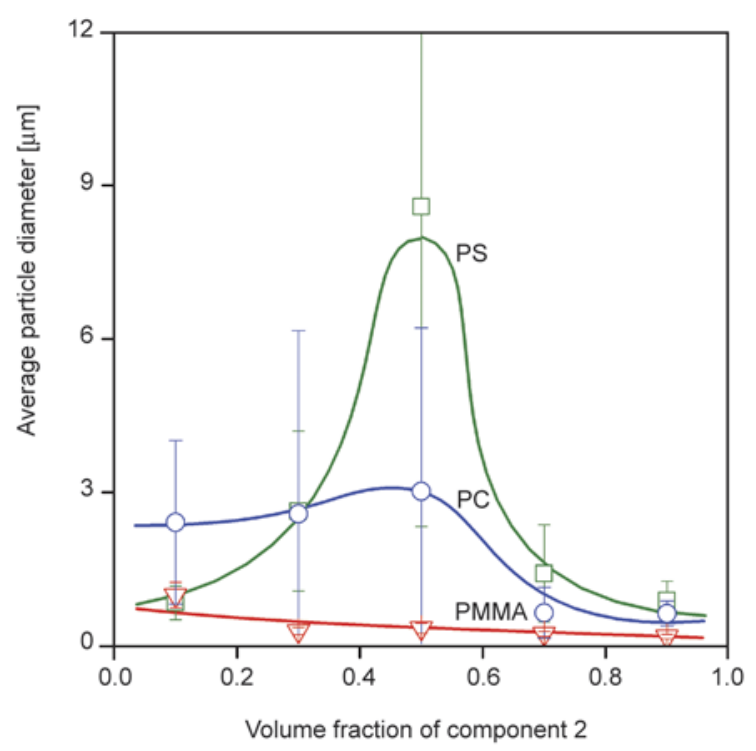

Figure 6. Differences in the size of the dispersed particles in PLA/thermoplastic polymer blends as a function of changing composition and the type of the second component; ( $\square$ ) PS, (०) PC, ( $\nabla)$ PMMA

results the strongest interaction develops between PLA and PMMA, while the weakest in the PLA/PS blends.

\subsection{Interactions}

Interaction, compatibility and/or miscibility are usually treated very qualitatively in many of the papers published on biopolymer blends [68]. Miscibility or immiscibility is usually estimated from SEM micrographs similar to those shown in Figures 4 and 5. A more sophisticate approach is based on the determination of glass transition temperature(s). The blend is declared miscible if it possesses a single glass transition temperature between that of the components, while two $T_{\mathrm{g}} \mathrm{s}$ are detected in immiscible blends corresponding to phases rich in the two components. The two transition temperatures shift towards each other in an extent depending on interactions and the mutual miscibility of the phases can be calculated from this shift with the method proposed by Kim and Burns [69].

$T_{\mathrm{g}} \mathrm{s}$ determined in two of the blend series are plotted against composition in Figure 7. Both pairs show rather peculiar behavior differing from the usual. The $T_{\mathrm{g}}$ of the PLA rich phase increases steeply and continuously, while that of the phase rich in PMMA decreases with a smaller slope at least at the beginning for the PLA/PMMA blend. The two $T_{\mathrm{g}} \mathrm{s}$ indicate heterogeneous, dispersed structure confirmed also by the SEM micrographs of Figures 4 and 5, 


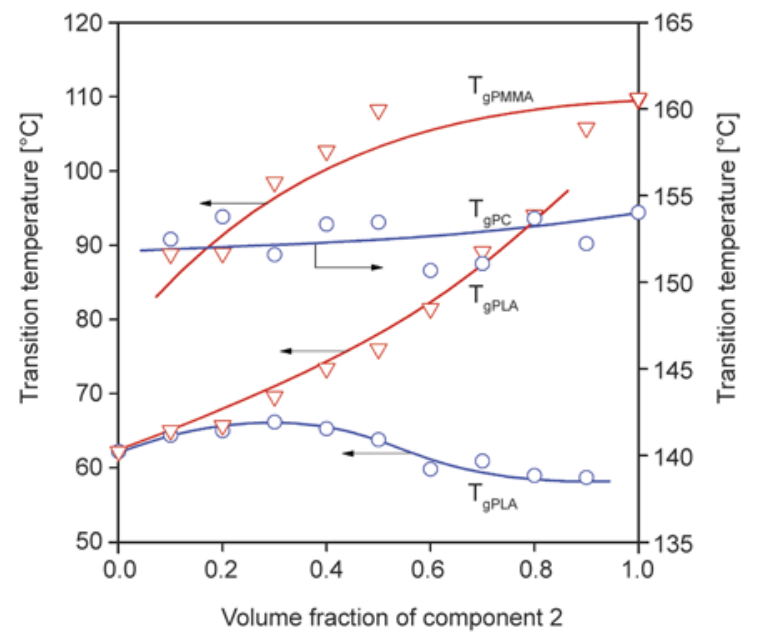

Figure 7. Effect of composition on the glass transition temperature of two series of blends; (O) PC, $(\nabla)$ PMMA

while the strong composition dependence shows the development of rather strong interactions between the components. Accordingly, the mutual miscibility of the phases must be relatively large. On the other hand, the composition dependence of the two transitions appearing on the DMA traces of the PLA/PC blend is much weaker than in the PLA/ PMMA blends. The $T_{\mathrm{g}}$ of the PC phase is almost constant, does not change, or changes only 1 or $2^{\circ} \mathrm{C}$ throughout the entire composition range. The composition dependence of the glass transition of PLA, on the other hand, is rather strange. It increases at small PC contents as expected, but decreases considerably above 0.4 volume fraction of PC. The asymmetric composition dependence of structure might be related to this decrease (see Figure 6), to the change in interaction and miscibility with composition. Nevertheless, based on these data interaction cannot be estimated quantitatively, interaction parameter or mutual miscibility is difficult or impossible to calculate by the Kim and Burns [69] approach.

Miscibility can also be estimated from component properties using the simple approach of group con- tributions, which yield the solubility parameter of the components, as described by Small [70], Hoy [71] and Hoftyzer and Van Krevelen [72]. We determined the solubility parameters of PLA and the thermoplastic polymers according to the method of Hoftyzer and Van Krevelen using Equations (1) to (4) [72]:

$$
\begin{aligned}
& \delta_{\mathrm{d}}=\frac{\sum F_{\mathrm{di}}}{V} \\
& \delta_{\mathrm{p}}=\frac{\sqrt{\sum F_{\mathrm{pi}}{ }^{2}}}{V} \\
& \delta_{\mathrm{h}}=\frac{\sqrt{\sum E_{\mathrm{hi}}}}{V} \\
& \delta=\sqrt{\delta_{\mathrm{d}}^{2}+\delta_{\mathrm{p}}+\delta_{\mathrm{h}}^{2}}
\end{aligned}
$$

where $F_{\mathrm{di}}$ and $F_{\mathrm{pi}}$ are group contributions, $\delta_{\mathrm{d}}, \delta_{\mathrm{p}}, \delta_{\mathrm{h}}$ the dispersion, polar and hydrogen bonding components of solubility parameter, while $\delta$ the total solubility parameter. $E_{\mathrm{hi}}$ is the hydrogen bonding energy, while $V$ refers to the molar volume of the repeating unit. The Flory-Huggins interaction parameter $\left(\chi_{2,3}\right)$ can be derived from the solubility parameter of the components by using Equation (5) [58]:

$\chi_{23}=\frac{V_{\mathrm{r}}}{R T}\left(\delta_{2}-\delta_{3}\right)^{2}$

where $\delta_{2}$ and $\delta_{3}$ are the solubility parameters of the components, $V_{\mathrm{r}}$ is a reference volume, which is the molar volume of a PLA repeating unit in our case, $R$ the universal gas constant and $T$ absolute temperature. The approach is very simple and has several limitations. For example, Equation (5) always yields positive values, although negative $\chi$ values also exist. Very small $\chi_{23}$ values imply good interaction. The results of the calculations are collected in Table 1 and they confirm our previous conclusions about interactions in the three series of blends.

\begin{tabular}{|c|c|c|c|c|c|}
\hline \multirow{2}{*}{ Blend } & \multirow{2}{*}{$\begin{array}{c}\text { Particle size } \\
{[\mu \mathrm{m}]}\end{array}$} & \multirow{2}{*}{$\begin{array}{c}\text { Solvent uptake } \\
\chi\end{array}$} & \multirow{2}{*}{$\begin{array}{c}\text { Calculated }^{\mathrm{c}} \\
\chi\end{array}$} & \multicolumn{2}{|c|}{ Tensile testing } \\
\hline & & & & Parameter B & Parameter $\mathbf{C}$ \\
\hline PS & 2.9 & $0.82^{\mathrm{a}}$ & 0.32 & 2.38 & 23.3 \\
\hline PC & 1.9 & $-0.35^{\mathrm{b}}$ & 0.13 & 3.03 & 30.0 \\
\hline PMMA & 0.4 & $-0.94^{b}$ & 0.08 & 3.23 & 35.3 \\
\hline
\end{tabular}

Another approach for the quantitative estimation of interactions is the measurement of solvent absorption

Table 1. Quantities related to component interactions in PLA blends

a: based on solvent uptake measurements in DMSO vapor

b:based on solvent uptake measurements in decane vapor

c: from solubility parameters calculated according to the group contributions of Hoftyzer and Van Krevelen 
in the components and the blends. The Flory-Huggins interaction parameter can be calculated from equilibrium solvent uptake by Equation (6) [58]:

$$
\begin{aligned}
\ln a_{1} & =\ln \varphi_{1}+\left(1-\varphi_{1}\right)+\left(\chi_{12} \varphi_{2}+\chi_{13} \varphi_{3}\right)\left(1-\varphi_{1}\right) \\
& -\chi_{23}^{\prime} \varphi_{2} \varphi_{3}
\end{aligned}
$$

where $a_{1}$ is the activity of the solvent, $\varphi_{1}$ its volume fraction in the blend at equilibrium, while $\chi_{12}$ and $\chi_{13}$ are the interaction parameters of the two-component solvent/polymer systems. $\chi_{23}^{\prime}$ is related to the polymer/polymer interaction parameter by Equation (7) [73]

$\chi_{23}^{\prime}=\chi_{23} \frac{V_{1}}{V_{2}}$

where $V_{1}$ and $V_{2}$ are the molar volumes of the solvent and polymer 2, respectively. We refrain from presenting details of the absorption experiments and equilibrium solvent uptake, but in Figure 8 we show the composition dependence of the Flory-Huggins interaction parameter determined by solvent absorption for the three series of blends. The smallest and negative interaction parameters were obtained for the PLA/PMMA blend, somewhat larger, close to zero for the PC and relative large positive values for the PLA/PS blends. These results are in accordance with the particle sizes determined in the SEM study (see Figure 6) and agree well also with the strength of the blends (Figure 3).

The above conclusion and earlier experience showed that interactions and miscibility are closely related

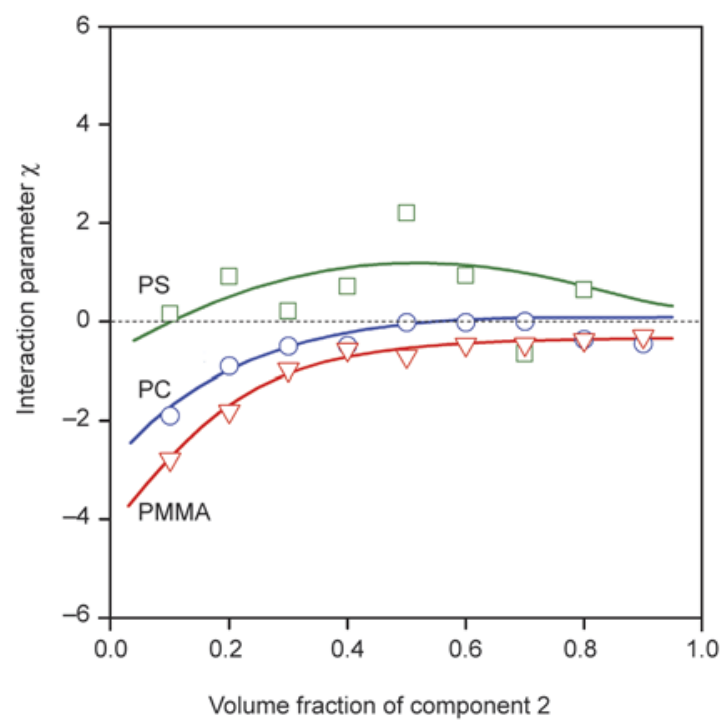

Figure 8. Composition dependence of the Flory-Huggins interaction parameter determined from solvent uptake; ( $\square)$ PS, ( $)$ ) PC, ( $\nabla)$ PMMA to structure and mechanical properties. A model developed earlier first for particulate filled polymers $[74,75]$ then adapted to blends $[59,60]$ allows the determination of a parameter related to interaction. According to the model the composition dependence of tensile strength can be expressed as shown by Equation (8) [75]

$\sigma_{\mathrm{T}}=\sigma_{\mathrm{T}_{0}} \lambda^{\mathrm{n}} \frac{1-\varphi_{\mathrm{d}}}{1+2.5 \varphi_{\mathrm{d}}} \exp \left(B_{\mathrm{T}} \varphi_{\mathrm{d}}\right)$

where $\sigma_{\mathrm{T}}$ and $\sigma_{\mathrm{T}}$ are the true tensile strength $\left(\sigma_{\mathrm{T}}=\right.$ $\left.\sigma \lambda, \lambda=L / L_{0}\right)$ of the heterogeneous polymeric system (blend or composite) and the matrix respectively, $n$ is a parameter expressing the strain hardening characteristics of the matrix, and $B$ is related to the load bearing capacity of the dispersed phase $[59,74,75]$. This latter is determined by interactions as well as by the inherent properties of the components as expressed by Equation (9)

$B=\ln \left(C \frac{\sigma_{\mathrm{T}_{\mathrm{d}}}}{\sigma_{\mathrm{T}_{0}}}\right)$

where $\sigma_{\mathrm{T}_{\mathrm{d}}}$ is the strength of the dispersed phase, while $C$ is related to stress transfer between the phases, i.e. interactions, and was found to correlate inversely with the Flory-Huggins interaction parameter [60].

According to the model, if we plot the natural logarithm of reduced tensile strength $\left[\sigma_{\mathrm{T}_{\text {red }}}=\right.$ $\left.\sigma_{\mathrm{T}}(1+2.5 \varphi) / \lambda^{\mathrm{n}} /(1-\varphi)\right]$ against composition we should obtain a straight line the slope of which is parameter $B$ and from that we can easily calculate $C$. In Figure 9 the strength of the PLA/PC composites was plotted against composition in the way suggested by Equation (8). We obtain straight lines indeed, i.e. the approach works and $C$ can be calculated. Naturally, we can and must draw two lines and determine two $B$ and $C$ values for the two sides of the composition range, since the model assumes a heterogeneous, dispersed structure. The two different $B$ values can yield the same or very similar $C$ values, since the inherent strength of the matrix is usually different [see Equation (9)]. Average particle size, interaction parameters determined from solvent adsorption and by the method of Hoftyzer and Van Krevelen [72], as well as average $B$ and $C$ values are listed in Table 1. All quantities related to component interactions agrees surprisingly well, especially if we consider the simplicity of the approaches used. All of them indicate very good 


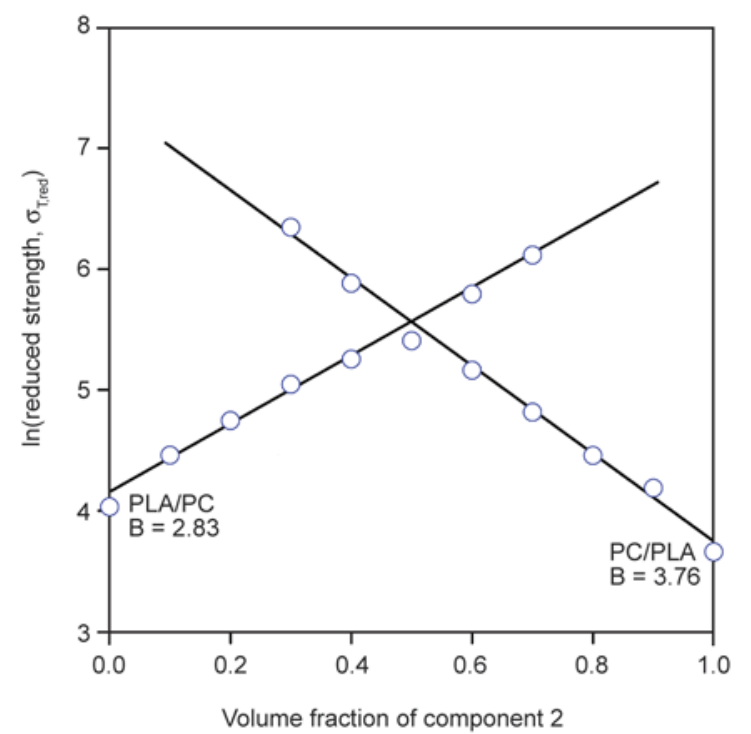

Figure 9. Determination of parameter $B$ (see Equation (8)) for the PLA/PC blend; the calculation of the two $B$ parameters assumes PLA (left line) and PC (right line) matrix, respectively

interactions in the PMMA, weaker in the PC and relatively poor in the PS blends.

\subsection{Miscibility-structure-property correlations}

The existence of the correlations mentioned in the heading of the section is an accepted fact, but quantitative relationships are not available practically at all. It is known, though, that the size of dispersed particles depends, among others, on interfacial tension which can be related to the Flory-Huggins interaction parameter $[60,62,64,76]$. The relationship of these parameters is supported also by the results presented above and the data of Table 1 . The thickness of the interphase can also be related to the interaction parameter, thus the volume of the interphase and mechanical properties as well. The relationship between mechanical properties and interaction has been demonstrated above. Stronger interactions mean smaller particles, larger interface, thicker interphase, better stress transfer and larger strength even if the structure of the blend is heterogeneous. The relationships are clear qualitatively. However, along these lines quantitative correlations can be also established as shown earlier. Following the line of thought described above inverse correlation was predicted between parameter $C$ determined from mechanical properties and the Flory-Huggins interaction parameter. Figure 10 shows the correlation for a number of blends studied earlier $[60,75$, 77]. $\chi$ was determined by solvent uptake and $C$ determined in the way described above. The general

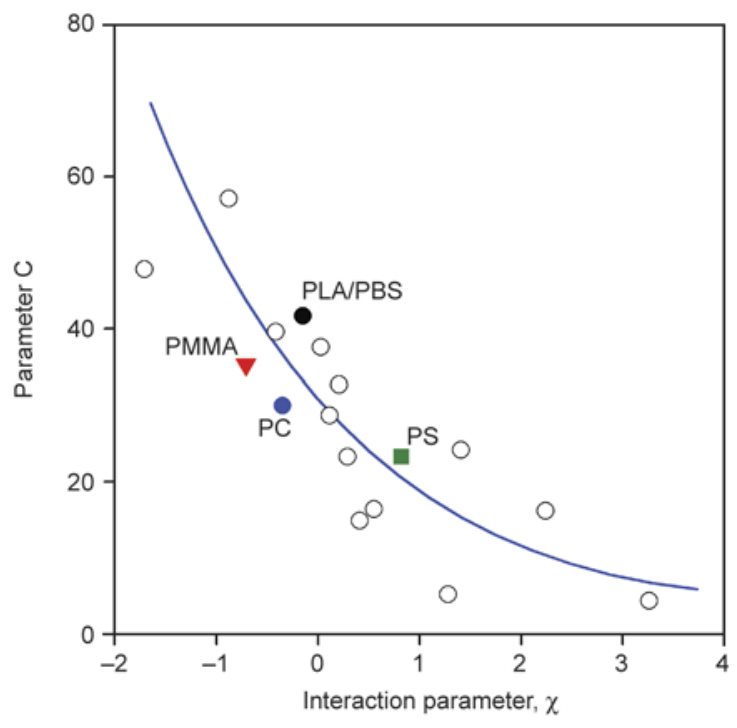

Figure 10. General correlation between component interactions $(\chi)$ and mechanical properties (parameter $C$ ) for a wide variety of blends; (O) results of earlier studies [60, 75], (•) PLA/PBS, data taken from the literature [77]

correlation is clear and the PLA blends studied in this project fit it quite well. Data were taken from the literature for the PLA/poly(butyl succinate) (PLA/ PBS) biopolymer blend and it also agrees with the rest of the results. Figure 10 proves the existence of the correlations discussed here and provides a means to predict the behavior of most polymer blends including those of biopolymers with acceptable accuracy.

\section{Conclusions}

The study of PLA blends prepared with three commercial polymers having differing chemical structure showed that the structure and properties of the blends cover a wide range. All three blends have heterogeneous structure, but the size of the dispersed particles differs by an order of magnitude indicating dissimilar interactions for the corresponding pairs. Properties change accordingly, the blend containing the smallest dispersed particles has the largest tensile strength, while PLA/PS blends with the coarsest structure have the smallest. The latter blends are also very brittle. Component interactions were estimated by four different methods, the determination of the size of the dispersed particles, the calculation of the Flory-Huggins interaction parameter from solvent absorption, from solubility parameters, and by the quantitative evaluation of the composition dependence of tensile strength. All approaches led to the same result indicating strong 
interaction for the PLA/PMMA pair and weak for PLA and PS. A general correlation was established between interactions and the mechanical properties of the blends. The results prove that PLA/PMMA blends possess adequate property combination to use them in the automotive and electronic industry.

\section{Acnowledgements}

József Selinga is acknowledged for his help in the preparation of the blends. We are grateful for the assistance of József Hári in the preparation of the SEM micrographs. The financial support of the National Scientific Research Fund of Hungary (OTKA Grant No. K 101124) for the research on heterogeneous polymer systems is much appreciated.

\section{References}

[1] Markarian J.: Biopolymers present new market opportunities for additives in packaging. Plastics, Additives and Compounding, 10, 22-25 (2008). DOI: $10.1016 / \mathrm{S} 1464-391 X(08) 70091-6$

[2] Sawyer D. J.: Bioprocessing - No longer a field of dreams. Macromolecular Symposia, 201, 271-282 (2003).

DOI: $10.1002 /$ masy.200351130

[3] Dorgan J. R., Lehermeier H. J., Palade L-I., Cicero J.: Polylactides: Properties and prospects of an environmentally benign plastic from renewable resources. Macromolecular Symposia, 175, 55-66 (2001).

DOI: $10.1002 / 1521-3900(200110) 175: 1<55:: A I D-$

$$
\text { MASY55>3.0.CO;2-K }
$$

[4] Auras R., Harte B., Selke S.: An overview of polylactides as packaging materials. Macromolecular Bioscience, 4, 835-864 (2004).

DOI: $10.1002 / \mathrm{mabi} .200400043$

[5] Kale G., Auras R., Singh S. P., Narayan R.: Biodegradability of polylactide bottles in real and simulated composting conditions. Polymer Testing, 26, 10491061 (2007).

DOI: 10.1016/j.polymertesting.2007.07.006

[6] Perego G., Cella G. D.: Mechanical properties. in 'Poly(lactic acid): Synthesis, structures, properties, processing, and applications' (eds.: Auras R., Lim L-T., Selke S., Tsuji H.) Wiley, Hoboken, 141-153 (2010). DOI: 10.1002/9780470649848.ch11

[7] Lemmouchi Y., Murariu M., Dos Santos A. M., Amass A. J., Schacht E., Dubois P.: Plasticization of poly(lactide) with blends of tributyl citrate and low molecular weight poly(D,L-lactide)-b-poly(ethylene glycol) copolymers. European Polymer Journal, 45, 28392848 (2009).

DOI: $10.1016 /$ j.eurpolymj.2009.07.006
[8] Pillin I., Montrelay N., Grohens Y.: Thermo-mechanical characterization of plasticized PLA: Is the miscibility the only significant factor? Polymer, 47, 46764682 (2006). DOI: 10.1016/j.polymer.2006.04.013

[9] Martin O., Avérous L.: Poly(lactic acid): Plasticization and properties of biodegradable multiphase systems. Polymer, 42, 6209-6219 (2001).

DOI: $10.1016 / \mathrm{S} 0032-3861(01) 00086-6$

[10] Ljungberg N., Wesslén B.: Tributyl citrate oligomers as plasticizers for poly (lactic acid): Thermo-mechanical film properties and aging. Polymer, 44, 7679-7688 (2003).

DOI: 10.1016/j.polymer.2003.09.055

[11] Wang N., Zhang X., Ma X., Fang J.: Influence of carbon black on the properties of plasticized poly(lactic acid) composites. Polymer Degradation and Stability, 93, 1044-1052 (2008). DOI: 10.1016/j.polymdegradstab.2008.03.023

[12] Paul M-A., Alexandre M., Degée P., Henrist C., Rulmont A., Dubois P.: New nanocomposite materials based on plasticized poly(L-lactide) and organo-modified montmorillonites: Thermal and morphological study. Polymer, 44, 443-450 (2003). DOI: $10.1016 / \mathrm{S} 0032-3861(02) 00778-4$

[13] Murariu M., Da Siva Ferreira A., Pluta M., Bonnaud L., Alexandre M., Dubois P.: Polylactide (PLA)-CaSO 4 composites toughened with low molecular weight and polymeric ester-like plasticizers and related performances. European Polymer Journal, 44, 3842-3852 (2008).

DOI: 10.1016/j.eurpolymj.2008.07.055

[14] Li B., Chen S-C., Qiu Z-C., Yang K-K., Tang S-P., Yu W-J., Wang Y-Z.: Synthesis of poly(lactic acid- $b-p$ dioxanone) block copolymers from ring opening polymerization of $p$-dioxanone by poly(L-lactic acid) macroinitiators. Polymer Bulletin, 61, 139-146 (2008). DOI: 10.1007/s00289-008-0939-1

[15] Hirata M., Kimura Y.: Thermomechanical properties of stereoblock poly(lactic acid)s with different PLLA/ PDLA block compositions. Polymer, 49, 2656-2661 (2008).

DOI: $10.1016 /$ j.polymer.2008.04.014

[16] Ho C-H., Wang C-H., Lin C-I., Lee Y-D.: Synthesis and characterization of TPO-PLA copolymer and its behavior as compatibilizer for PLA/TPO blends. Polymer, 49, 3902-3910 (2008).

DOI: $10.1016 /$ j.polymer.2008.06.054

[17] Mert O., Doganci E., Erbil H. Y., Dernir A. S.: Surface characterization of poly(L-lactic acid)-methoxy poly (ethylene glycol) diblock copolymers by static and dynamic contact angle measurements, FTIR, and ATRFTIR. Langmuir, 24, 749-757 (2008).

DOI: $10.1021 / 1 \mathrm{a} 701966 \mathrm{~d}$ 
[18] Södergård A., Stolt M.: Properties of lactic acid based polymers and their correlation with composition. Progress in Polymer Science, 27, 1123-1163 (2002). DOI: 10.1016/S0079-6700(02)00012-6

[19] Nagahama K., Nishimura Y., Ohya Y., Ouchi T.: Impacts of stereoregularity and stereocomplex formation on physicochemical, protein adsorption and cell adhesion behaviors of star-shaped 8-arms poly(ethylene glycol)-poly(lactide) block copolymer films. Polymer, 48, 2649-2658 (2007). DOI: $10.1016 /$ j.polymer.2007.03.017

[20] Gu S-Y., Zhang K., Ren J., Zhan H.: Melt rheology of polylactide/poly(butylene adipate-co-terephthalate) blends. Carbohydrate Polymers, 74, 79-85 (2008).

DOI: 10.1016/j.carbpol.2008.01.017

[21] Rohman G., Lauprêtre F., Boileau S., Guérin P., Grande D.: Poly(D,L-lactide)/poly(methyl methacrylate) interpenetrating polymer networks: Synthesis, characterization, and use as precursors to porous polymeric materials. Polymer, 48, 7017-7028 (2007).

DOI: $10.1016 /$ j.polymer.2007.09.044

[22] Pluta M., Jeszka J. K., Boiteux G.: Polylactide/montmorillonite nanocomposites: Structure, dielectric, viscoelastic and thermal properties. European Polymer Journal, 43, 2819-2835 (2007).

DOI: 10.1016/j.eurpolymj.2007.04.009

[23] Gorna K., Hund M., Vučak M., Gröhn F., Wegner G.: Amorphous calcium carbonate in form of spherical nanosized particles and its application as fillers for polymers. Materials Science and Engineering: A, 477, 217-225 (2008).

DOI: $10.1016 /$ j.msea.2007.05.045

[24] Bleach N. C., Nazhat S. N., Tanner K. E., Kellomäki M., Törmälä P.: Effect of filler content on mechanical and dynamic mechanical properties of particulate biphasic calcium phosphate-polylactide composites. Biomaterials, 23, 1579-1585 (2002).

DOI: 10.1016/S0142-9612(01)00283-6

[25] Bax B., Müssig J.: Impact and tensile properties of PLA/Cordenka and PLA/flax composites. Composites Science and Technology, 68, 1601-1607 (2008). DOI: 10.1016/j.compscitech.2008.01.004

[26] Kuan C-F., Kuan H-C., Ma C-C. M., Chen C-H.: Mechanical and electrical properties of multi-wall carbon nanotube/poly(lactic acid) composites. Journal of Physics and Chemistry of Solids, 69, 1395-1398 (2008).

DOI: $10.1016 /$ j.jpcs.2007.10.060

[27] Murariu M., Da SilvaFerreira A., Degée P., Alexandre M., Dubois P.: Polylactide compositions. Part 1: Effect of filler content and size on mechanical properties of PLA/calcium sulfate composites. Polymer, 48, 26132618 (2007).

DOI: $10.1016 /$ j.polymer.2007.02.067
[28] Pluta M., Murariu M., Da Silva Ferreira A., Alexandre M., Galeski A., Dubois P.: Polylactide compositions. II. Correlation between morphology and main properties of PLA/calcium sulfate composites. Journal of Polymer Science Part B: Polymer Physics, 45, 27702780 (2007).

DOI: $10.1002 /$ polb.21277

[29] Sobkowicz M. J., Feaver J. L., Dorgan J. R.: Clean and green bioplastic composites: Comparison of calcium sulfate and carbon nanospheres in polylactide composites. CLEAN - Soil, Air, Water, 36, 706-713 (2008). DOI: 10.1002/clen.200800076

[30] Kasuga T., Ota Y., Nogami M., Abe Y.: Preparation and mechanical properties of polylactic acid composites containing hydroxyapatite fibers. Biomaterials, 22, 19-23 (2001). DOI: $10.1016 / \mathrm{S} 0142-9612(00) 00091-0$

[31] Bucknall C. B.: Toughened plastics. Applied Science Publishers, London (1977).

[32] Olabisi O., Robeson L. M., Shaw M. T.: Polymer-polymer miscibility. Academic Press, New York (1979).

[33] Walsh D. J., Higgins J. S., Maconnachie A.: Polymer blends and mixtures. Martinus Nijhoff Publishers, Dordrecht (1985).

[34] Utracki L. A.: Polymer alloys and blends; Thermodynamics and rheology. Hanser, Munich (1989).

DOI: 10.1002/pi.4990250214

[35] Paul D. R., Bucknall. C. B.: Polymer blends: Formulation. Wiley, New York (2000).

[36] St-Pierre N., Favis B. D., Ramsay B. A., Ramsay J. A., Verhoogt H.: Processing and characterization of thermoplastic starch/polyethylene blends. Polymer, 38, 647-655 (1997).

DOI: $10.1016 / \mathrm{S} 0032-3861(97) 81176-7$

[37] Kim M.: Evaluation of degradability of hydroxypropylated potato starch/polyethylene blend films. Carbohydrate Polymers, 54, 173-181 (2003).

DOI: $10.1016 / \mathrm{S} 0144-8617(03) 00169-3$

[38] Rodriguez-Gonzalez F. J., Ramsay B. A., Favis B. D.: High performance LDPE/thermoplastic starch blends: A sustainable alternative to pure polyethylene. Polymer, 44, 1517-1526 (2003).

DOI: $10.1016 / \mathrm{S} 0032-3861(02) 00907-2$

[39] Li H., Huneault M. A.: Comparison of sorbitol and glycerol as plasticizers for thermoplastic starch in TPS/ PLA blends. Journal of Applied Polymer Science, 119, 2439-2448 (2011). DOI: $10.1002 / a p p .32956$

[40] Huneault M. A., Li H.: Morphology and properties of compatibilized polylactide/thermoplastic starch blends. Polymer, 48, 270-280 (2007). DOI: $10.1016 /$ j.polymer.2006.11.023

[41] Chapleau N., Huneault M. A., Li H.: Biaxial orientation of polylactide/thermoplastic starch blends. International Polymer Processing, 22, 402-409 (2007). DOI: $10.3139 / 217.2070$ 
[42] Mihai M., Huneault M. A., Favis B. D., Li H.: Extrusion foaming of semi-crystalline PLA and PLA/thermoplastic starch blends. Macromolecular Bioscience, 7, 907-920 (2007).

DOI: 10.1002/mabi.200700080

[43] Zhang J-F., Sun X.: Mechanical properties of poly(lactic acid)/starch composites compatibilized by maleic anhydride. Biomacromolecules, 5, 1446-1451 (2004). DOI: $10.1021 / \mathrm{bm} 0400022$

[44] Wang L., Ma W., Gross R. A., McCarthy S. P.: Reactive compatibilization of biodegradable blends of poly (lactic acid) and poly( $\varepsilon$-caprolactone). Polymer Degradation and Stability, 59, 161-168 (1998).

DOI: 10.1016/S0141-3910(97)00196-1

[45] Kovács J. G., Tábi T.: Examination of starch preprocess drying and water absorption of injection-molded starchfilled poly(lactic acid) products. Polymer Engineering and Science, 51, 843-850 (2011).

DOI: $10.1002 /$ pen.21900

[46] Cai H., Yu J., Qiu Z.: Miscibility and crystallization of biodegradable poly(3-hydroxybutyrate-co-3-hydroxyhexanoate)/poly(vinyl phenol) blends. Polymer Engineering and Science, 52, 233-241 (2012).

DOI: 10.1002/pen.22069

[47] Yang J., Liu M. K., Zhang B., Chen X. D., Fu R. W., Zhang M. Q.: Intrinsic fluorescence studies of compatibility in thermoplastic phenol formaldehyde resin/ poly( $\varepsilon$-caprolactone) blends. Express Polymer Letters, 5, 698-707 (2011).

DOI: $10.3144 /$ expresspolymlett.2011.68

[48] Hinüber C., Häussler L., Vogel R., Brünig H., Heinrich G., Werner C.: Hollow fibers made from a poly(3hydroxybutyrate)/poly- $\varepsilon$-caprolactone blend. Express Polymer Letters, 5, 643-652 (2011).

DOI: $10.3144 /$ expresspolymlett.2011.62

[49] Wu D., Yuan L., Laredo E., Zhang M., Zhou W.: Interfacial properties, viscoelasticity, and thermal behaviors of poly(butylene succinate)/polylactide blend. Industrial and Engineering Chemistry Research, 51, 2290-2298 (2012).

DOI: $10.1021 /$ ie2022288

[50] Park J. W., Im S. S.: Phase behavior and morphology in blends of poly(L-lactic acid) and poly(butylene succinate). Journal of Applied Polymer Science, 86, 647655 (2002).

DOI: 10.1002/app.10923

[51] Furukawa T., Sato H., Murakami R., Zhang J. M., Noda I., Ochiai S., Ozaki Y.: Comparison of miscibility and structure of poly(3-hydroxybutyrate-co-3hydroxyhexanoate)/poly(L-lactic acid) blends with those of poly(3-hydroxybutyrate)/poly(L-lactic acid) blends studied by wide angle X-ray diffraction, differential scanning calorimetry, and FTIR microspectroscopy. Polymer, 48, 1749-1755 (2007).

DOI: $10.1016 /$ j.polymer.2007.01.020
[52] Wasantha L. M., Gunaratne K., Shanks R. A.: Miscibility, melting, and crystallization behavior of poly(hydroxybutyrate) and poly(D,L-lactic acid) blends. Polymer Engineering and Science, 48, 1683-1692 (2008). DOI: $10.1002 /$ pen. 21051

[53] Tan Z. J., Vancso G. J.: Polymer-polymer interaction parameters by inverse gas chromatography: A novel molecular interpretation of nonrandom partitioning of solvent probes in polymer blends. Macromolecular Theory and Simulations, 6, 467-478 (1997). DOI: $10.1002 /$ mats.1997.040060211

[54] Choe S., Cha Y-J., Lee H-S., Yoon J. S., Choi H. J.: Miscibility of poly(3-hydroxybutyrate-co-3-hydroxyvalerate) and poly(vinyl chloride) blends. Polymer, 36, 4977-4982 (1995).

DOI: 10.1016/0032-3861(96)81624-7

[55] Pereira A. G. B., Gouveia R. F., de Carvalho G. M., Rubira A. F., Muniz E. C.: Polymer blends based on PEO and starch: Miscibility and spherulite growth rate evaluated through DSC and optical microscopy. Materials Science and Engineering C, 29, 499-504 (2009). DOI: $10.1016 /$ j.msec.2008.09.009

[56] Zhang L. L., Goh S. H., Lee S. Y., Hee G. R.: Miscibility, melting and crystallization behavior of two bacterial polyester/poly(epichlorohydrin-co-ethylene oxide) blend systems. Polymer, 41, 1429-1439 (2000).

DOI: 10.1016/S0032-3861(99)00320-1

[57] Imre B., Pukánszky B.: Compatibilization in bio-based and biodegradable polymer blends. European Polymer Journal, 49, 1215-1233 (2013).

DOI: $10.1016 /$ j.eurpolymj.2013.01.019

[58] Szabó P., Epacher E., Földes E., Pukánszky B.: Miscibility, structure and properties of PP/PIB blends. Materials Science and Engineering, 383, 307-315 (2004). DOI: $10.1016 /$ j.msea.2004.04.035

[59] Pukánszky B., Tüdős F.: Miscibility and mechanical properties of polymer blends. Makromolekulare Chemie, Macromolecular Symposia, 38, 221-231 (1990). DOI: 10.1002/masy.19900380118

[60] Fekete E., Pukánszky B., Peredy Z.: Mutual correlations between parameters characterizing the miscibility, structure and mechanical properties of polymer blends. Die Angewandte Makromolakulare Chemie, 199, 87-101 (1992). DOI: 10.1002/apmc.1992.051990108

[61] Pukánszky B., Fortelný I., Kovář J., Tüdős F.: Particle break-up and coalescence in heterogeneous PP/EPDM blends; Effect of particle size on some mechanical properties. Plastics, Rubber and Composites Processing and Applications, 15, 31-38 (1991).

[62] Taylor G. I.: The formation of emulsions in definable fields of flow. Proceedings of the Royal Society A, 146, 501-523 (1934).

DOI: $10.1098 /$ rspa.1934.0169

[63] Elmendorp J. J., Maalcke R. J.: Some microrheological aspects of polymer blending. Materials Science Monographs, 21, 219-230 (1984). 
[64] Tokita N.: Analysis of morphology formation in elastomer blends. Rubber Chemistry and Technology, 50, 292-300 (1977).

DOI: $10.5254 / 1.3535144$

[65] Danesi S.: Principles and technologies of polymer blending. in 'Polymer blends' (eds.: Galeski A., Martuscelli A.) Plenum Press, New York, Vol 2, 35-40 (1984).

DOI: $10.1007 / 978-1-4899-1831-43$

[66] Heikens D., Barentsen W.: Particle dimensions in polystyrene/polyethylene blends as a function of their melt viscosity and of the concentration of added graft copolymer. Polymer, 18, 69-72 (1977).

DOI: 10.1016/0032-3861(77)90264-6

[67] Fortelný I., Kovář J.: Droplet size of the minor component in the mixing of melts of immiscible polymers. European Polymer Journal, 25, 317-319 (1989). DOI: 10.1016/0014-3057(89)90239-5

[68] Zhang K., Ran X., Wang X., Han C., Wen X., Zhuang Y., Dong L.: Improvement in toughness and crystallization of poly(L-lactic acid) by melt blending with poly (epichlorohydrin-co-ethylene oxide). Polymer Engineering and Science, 51, 2370-2380 (2011).

DOI: 10.1002/pen.22009

[69] Kim W. N., Burns C. M.: Blends of polycarbonate and poly(methyl methacrylate) and the determination of the polymer-polymer interaction parameter of the two polymers. Macromolecules, 20, 1876-1882 (1987).

[70] Small P. A.: Some factors affecting the solubility of polymers. Journal of Applied Chemistry, 3, 71-80 (1953).

DOI: $\underline{10.1002 / j \mathrm{jctb} .5010030205}$
[71] Hoy K. L.: New values of the solubility parameters from vapor pressure data. Journal of Paint Technology, 42, 76-118 (1970).

[72] Hoftyzer P. J., Van Krevelen D. W.: Cohesive properties and solubility. in 'Properties of polymers' (ed.: Van Krevelen D. W.) Elsevier, New York, 152-155 (1976).

[73] Hopfenberg H. B., Paul D. R.: Transport phenomena in polymer blends. in 'Polymer blends' (eds.: Paul D. R., Newman S.) Academic Press, New York, Vol. 1, 445489 (1978).

[74] Pukánszky B., Turcsányi B., Tüdős F.: Effect of interfacial interaction on the tensile yield stress of polymer composites. in 'Interfaces in polymer, ceramic, and metal matrix composites' (ed.: Ishida H.) Elsevier, New York, 467-477 (1988).

[75] Pukánszky B.: Influence of interface interaction on the ultimate tensile properties of polymer composites. Composites, 21, 255-262 (1990). DOI: 10.1016/0010-4361(90)90240-W

[76] Fortelný I., Kamenická P., Kovář J.: Effect of the viscosity of components on the phase structure and impact strength of polypropylene/ethylene-propylene elastomer blends. Die Angewandte Markomolekulare Chemie, 164, 125-141 (1988).

DOI: 10.1002/apmc.1988.051640110

[77] Bhatia A., Gupta R., Bhattacharya S. N., Choi H. J.: Compatibility of biodegradable poly (lactic acid) (PLA) and poly (butylene succinate) (PBS) blends for packaging application. Korea - Australia Rheology Journal, 19, 125-131 (2007). 